\title{
Gender Disparity Among NBA and WNBA Team Physicians (112)
}

Mary Mulcahey, $\mathrm{MD}^{1}$, Andrew Hinkle, BS ${ }^{1}$, Symone Brown

Tulane University School of Medicine ${ }^{1}$

Objectives: Female physicians are underrepresented across a broad range of medical specialties, especially at senior levels. Previous research demonstrated poor representation of women in sports medicine leadership roles in the National Collegiate Athletic Association (NCAA) compared to their male colleagues. The purpose of this study was to evaluate the distribution of men and women among team physicians on the medical staffs of National Basketball Association (NBA) and Women's National Basketball Association (WNBA) teams in the last 10 years and assess regional differences in representation of female physicians.

Methods: A Google search of publicly available data regarding team physician gender, medical specialty, and medical degree was conducted in October 2019 for team physicians in the NBA and WNBA over the last 10 years. Descriptive statistics were used to analyze the data. This data was then stratified by region of country in which NBA/WNBA franchises are located to provide regional comparison of team physician characteristics.

Results: We identified 125 team physicians for NBA franchises. 122 (97.6\%) were male and 3 (2.4\%) were female. In the WNBA, a total of 28 physicians were identified. $20(71.4 \%)$ were male and $8(28.6 \%)$ were female. Osteopathic physicians accounted for 5 $(4 \%)$ and $2(7.1 \%)$ of the physicians associated with NBA and WNBA franchises, respectively. Demographic findings of NBA and WNBA team physicians are demonstrated in Table 1 . The Northeast had the highest proportion of female team physicians, with 5 of $18(27.8 \%)$.

Conclusions: This study demonstrates a substantial difference in the number of female physicians with leadership roles in both the NBA and WNBA compared to male physicians. It is important to try to understand what barriers female physicians face in their pursuit of leadership positions in sports medicine and to implement strategies to provide equal opportunities to both male and female physicians.

The Orthopaedic Journal of Sports Medicine, 9(10)(suppl 5)

DOI: $10.1177 / 2325967121500262$

(C) The Author(s) 2021

This open-access article is published and distributed under the Creative Commons Attribution - NonCommercial - No Derivatives License (https://creativecommons.org/licenses/by-nc-nd/4.0/), which permits the noncommercial use, distribution, and reproduction of the article in any medium, provided the original author and source are credited. You may not alter, transform, or build upon this article without the permission of the Author(s). For article reuse guidelines, please visit SAGE's website at http://www.sagepub.com/journals-permissions. 